\title{
Online Measurement of Oxygen-Dependent Enzyme Reaction Kinetics
}

\author{
Meissner, Murray Peter; Nordblad, Mathias; Woodley, John M
}

Published in:

ChemBioChem

Link to article, DOI:

$10.1002 /$ cbic. 201700577

Publication date:

2018

Document Version

Peer reviewed version

Link back to DTU Orbit

Citation (APA):

Meissner, M. P., Nordblad, M., \& Woodley, J. M. (2018). Online Measurement of Oxygen-Dependent Enzyme Reaction Kinetics. ChemBioChem, 19(1), 106-113 . https://doi.org/10.1002/cbic.201700577

\section{General rights}

Copyright and moral rights for the publications made accessible in the public portal are retained by the authors and/or other copyright owners and it is a condition of accessing publications that users recognise and abide by the legal requirements associated with these rights.

- Users may download and print one copy of any publication from the public portal for the purpose of private study or research.

- You may not further distribute the material or use it for any profit-making activity or commercial gain

- You may freely distribute the URL identifying the publication in the public portal

If you believe that this document breaches copyright please contact us providing details, and we will remove access to the work immediately and investigate your claim. 


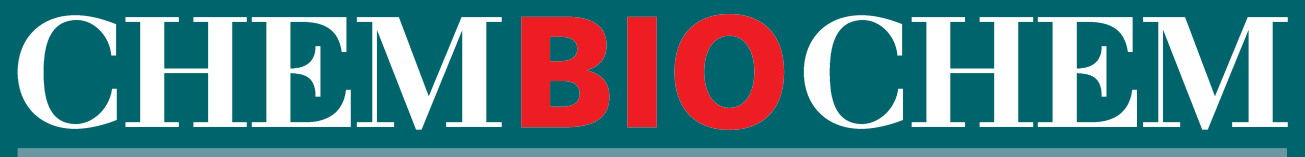

SYNTHETIC BIOLOGY \& BIO-NANOTECHNOLOGY

\section{Accepted Article}

Title: Online Measurement of Oxygen-Dependent Enzyme Reaction Kinetics

Authors: Murray P. Meissner, Mathias Nordblad, and John M. Woodley

This manuscript has been accepted after peer review and appears as an Accepted Article online prior to editing, proofing, and formal publication of the final Version of Record (VoR). This work is currently citable by using the Digital Object Identifier (DOI) given below. The VoR will be published online in Early View as soon as possible and may be different to this Accepted Article as a result of editing. Readers should obtain the VoR from the journal website shown below when it is published to ensure accuracy of information. The authors are responsible for the content of this Accepted Article.

To be cited as: ChemBioChem 10.1002/cbic.201700577

Link to VoR: http://dx.doi.org/10.1002/cbic.201700577 
WILEY-VCH

\title{
Online Measurement of Oxygen-Dependent Enzyme Reaction
} Kinetics

\author{
Murray P. Meissner, ${ }^{[a]}$ Mathias Nordblad, ${ }^{[a]}$ and John M. Woodley ${ }^{*[a]}$
}

\begin{abstract}
As the application of biocatalysis to complement conventional chemical and catalytic approaches continues to expand, an increasing number of reactions involve poorly-water soluble substrates. At required industrial concentrations necessary for industrial implementation, this frequently leads to heterogeneous reaction mixtures composed of multiple phases. Such systems are challenging to sample and therefore it is problematic to measure representative component concentrations. In this work we demonstrate and validate an online method for following the progress of oxygen-dependent reactions through accurate measurement of the oxygen mass balance in the gas-phase of a reactor. The method was successfully validated and demonstrated using two model reactions: firstly the oxidation of glucose by glucose oxidase and secondly the Baeyer-Villiger oxidation of macrocyclic ketones to lactones. Initial reaction rate constants and time-course progressions calculated from the oxygen mass balance were validated against conventional online methods of dissolved oxygen tension and $\mathrm{pH}$ titration measurements. A feasible operating window as well as the sensitivity to dynamic changes of reaction rates was established by controlling oxygen transfer via the operating parameters of the reactor. Such kinetic data forms the basis for reaction characterisation, from which bottlenecks may be made evident and directed improvement strategies can be identified and implemented.
\end{abstract}

\section{Introduction}

Conventional wisdom holds that the characterisation of enzymatic reactions is best performed by time-course experiments as close to industrially-relevant conditions as possible. The resulting reaction progress curves, under a range of defined conditions, reveal performance limitations (or bottlenecks), such as enzyme stability, substrate/product inhibition or mass transfer. ${ }^{[1 a, b]}$ Once identified, directed process ${ }^{[2]}$ and/or protein engineering ${ }^{[3]}$ strategies to address these bottlenecks may be identified and implemented. ${ }^{[4]}$ Hence, reaction characterisation is fundamental to identifying bottlenecks during enzymatic process development. ${ }^{[5,6]}$ It follows that if such information is gained at an early stage in process development, industrial implementation will proceed at a faster pace, which can alone determine the success of many processes, especially in the pharmaceutical industry. ${ }^{[7]}$ Central to this characterisation is the necessity for accurate analytics.

[a] Murray P. Meissner, Mathias Nordblad, John M. Woodley Department of Chemical and Biochemical Engineering Technical University of Denmark

Søltofts Plads, Building 229, 2800 Lyngby (Denmark)

E-mail: jw@kt.dtu.dk
Broadening the application of biocatalysis to a wider range of industrially useful substrates will require focus on how to deal with organic solvents and poorly water-soluble substrates. ${ }^{[8]}$ Indeed, industrially relevant substrate/product loadings in excess of $50 \mathrm{~g} \mathrm{~L}^{-1}$ will most often exceed solubility limits, or induce inhibition, frequently necessitating the need for additional water-immiscible solvent phases. ${ }^{[9-13]}$ This situation is increasingly common and brings the significant challenge of sampling heterogeneous mixtures, in such a way as to give representative and useful measurements. ${ }^{[14]}$

Oxidation reactions form an important class of reactions in organic chemistry. Chemocatalytic methods of performing oxidations suffer from numerous limitations such as the use of harmful oxidants, side reactions, and lack of regio- and stereoselectivity. ${ }^{[15]}$ Instead, oxygen-dependent enzymes present alternative catalysts, which are able to address many of these drawbacks. These enzymes fall under several classes such as oxidases, mono- and dioxygenases, dehydrogenases, and peroxidases. ${ }^{[16]}$ In particular, due to their use of molecular oxygen and high stereoselectivity, oxygen-dependent enzymes been earmarked for their application in synthetic and industrial chemistry. ${ }^{[17-19]}$ The continuous supply (and conversion) of oxygen during these reactions provides an alternative method for measuring reaction rate, not dependent on sampling the reaction medium. On this premise we decided to use this method for kinetic characterisation. Hence, the objective of the work presented here is to document a simple methodology to characterise oxygen-dependent reactions with poorly watersoluble components and/or two-liquid phases by eliminating the need for direct sampling of a multi-phasic reaction medium. The method is based on using the oxygen mass balance measured by online gas-phase analysis. The primary advantage of this method is that it is insensitive to sampling heterogeneity (due to non-ideal mixing of multi-phasic mixtures) since it measures solely in the gas-phase. Additionally, the method is generic for any oxygendependent reaction meaning it can cope with different substrates and the development of a new analysis method for each new compound can be avoided. Furthermore, as an online method it may also be used for process control because it yields real-time kinetic predictions. Inspired by similar applications of this approach in the fields of wastewater treatment, ${ }^{[20]}$ solid state fermentation $\mathrm{n}^{[21 \mathrm{a}, \mathrm{b}]}$ and in more conventional fermentations by means of measuring respiratory quotients, ${ }^{[22]}$ the application of this method to enzymatic reaction kinetic measurements is novel. Of particular interest is that the oxygen consumption rates (productivities) of enzyme-catalysed reactions in an industrial setting are up to two orders of magnitude higher than in the previous examples, increasing accuracy. 
In order to illustrate and validate the methodology we have first used the well-known, stable enzyme glucose oxidase (EC 1.1.3.4; GOx) to catalyse the oxidation of glucose to glucono1,5-lactone, which thereafter spontaneously hydrolyses to gluconic acid (Scheme 1). It should be noted that the effective 1:2 stoichiometry for oxygen:glucose conversion is due to the extra peroxide degradation loop catalysed by catalase (EC 1.11.1.6), which is unique to oxidase-based reactions.

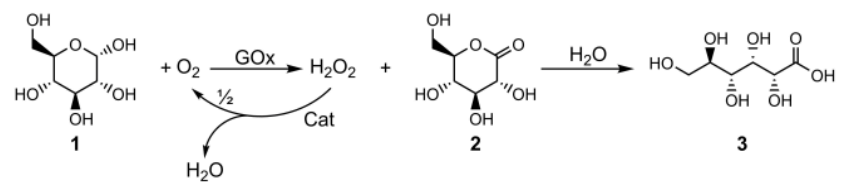

Scheme 1. Reaction scheme catalysed by glucose oxidase (GOx) and catalase (Cat), which is used to decompose hydrogen peroxide, a harmful reaction intermediate. 1 = D-Glucose; 2 = D-Glucono-1,5-lactone; 3 = D-Gluconic acid.

The accuracy of the gas-phase analytical equipment with respect to differing productivities (achieved by adjusting oxygen transfer rates (OTRs) and enzyme loading) was estimated by comparison with glucose analysis in liquid-phase samples by HPLC, and in this way, feasible operating windows for the method were found. In addition, estimating initial rates and time-course substrate consumptions by gas-phase measurements were also compared with other, more conventional online methods such as dissolved oxygen tension (DOT) and $\mathrm{pH}$ titration measurements. The inherent challenges of applying these more conventional approaches are also discussed. Lastly, the method is also applied to a more complex, heterogeneous reaction involving co-solvent, which was catalysed by a Baeyer-Villiger monooxygenase (BVMO). This reaction was the oxidation of macrocyclic ketone 4 to lactone $\mathbf{5}$ (Scheme 2) by cyclododecanone monooxygenase (EC 1.14.13.x; CDMO) from Rhodococcus ruber SC1. ${ }^{[23,24]}$ Cofactor regeneration was facilitated by glucose dehydrogenase (EC 1.1.1.47; GDH) catalysing the analogous reaction of GOx in
Scheme 1, however without need for molecular oxygen. The BVMO-catalysed reaction demonstrated not only the usefulness of such an online method for following reaction progress where standard liquid-phase sampling is made problematic, but also the generality of applying gas-phase mass balances to any system requiring oxygen. An explanation of the theory and nomenclature used in the application of this method follows in the Experimental Section.

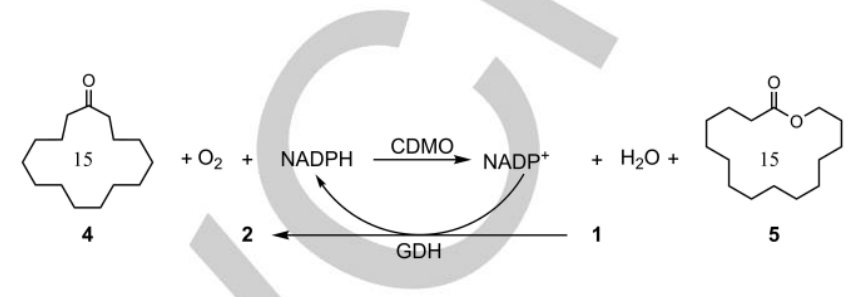

Scheme 2. Oxidation of macrocyclic ketones to lactones catalysed by cyclododecanone monooxygenase from Rhodococcus ruber SC1 (CDMO). Reduced nicotinamide phosphate (NADPH) cofactor was recycled using glucose dehydrogenase (GDH), which accepts D-glucose (1) as a co-substrate and produces D-glucono-1,5-lactone (2). 4 = cyclopentadecanone; $\mathbf{5}=$ cyclopentadecanolide.

\section{Results and Discussion}

\section{Oxygen mass balance method validation}

As a brief validation that time-course reaction progression and initial rate estimations made by oxygen mass balance in the gas phase correlate to standard HPLC analyses, an example of data output from gas-phase measurements is shown in Figure 1. The initial oxygen transfer rate calculated by the difference $\left(\dot{n}_{O 2, \text { in }}-\dot{n}_{O 2, a v g}\right) / V$ was found to be $33.42 \pm 0.54 \mathrm{mmol} \mathrm{L}^{-1} \mathrm{~h}^{-1}$ (mean $\pm 95 \mathrm{Cl}$ ). The predicted $R_{\text {glucose }}$ was therefore, from reaction stoichiometry, $66.84 \pm 1.08 \mathrm{mmol} \mathrm{L}^{-1} \mathrm{~h}^{-1}$, which was within a $98 \%$ agreement with the rate measured by HPLC $\left(68.19 \pm 2.05 \mathrm{mmol} \mathrm{L}^{-1} \mathrm{~h}^{-1}\right)$. Indeed, the closeness of prediction over the full time-course using gas-phase analysis can be seen in Figure 2 .

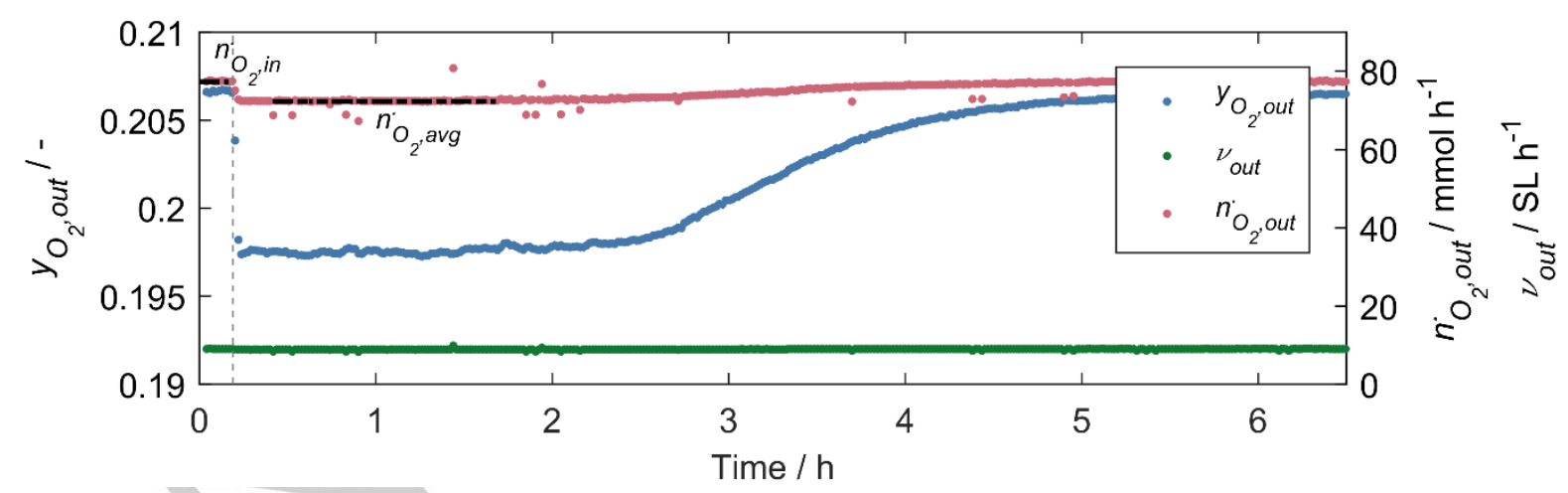

Figure 1. Measured total volumetric flow rate of gas in the outlet stream (green) and oxygen fraction in the off-gas (blue) as a function of time. The number of moles of oxygen (red) were calculated through the ideal gas law and the grey dashed line indicates reaction initiation by the addition of $200 \mathrm{mg} \mathrm{L}^{-1} \mathrm{GOx}$. $\mathrm{pH}$ was maintained at 7.5 by titration of $1 \mathrm{M} \mathrm{NaOH}$. Steady-state periods that were taken as references for initial rate calculations are indicated. Agitation rate $=1000$ rpm; aeration rate $=1.0 \mathrm{vvm}$. 


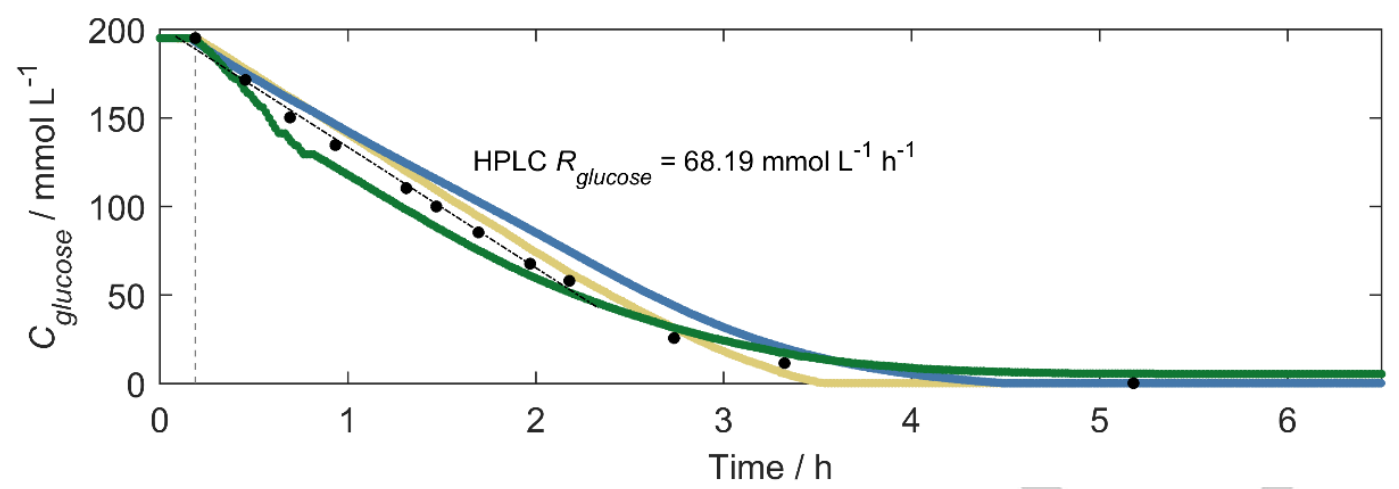

Figure 2. Predictions of dynamic glucose concentrations during a time-course experiment using the off-gas mass balance method (yellow), dissolved oxygen measurements (blue) and $\mathrm{pH}$ titration method (green) compared with measurements by HPLC (black circles). The grey dashed line indicates reaction initiation by the addition of $200 \mathrm{mg} \mathrm{L}^{-1} \mathrm{GOx}$. The reaction was performed in the absence of buffer with the titration of $1 \mathrm{M} \mathrm{NaOH}$ for pH control. Agitation rate $=1000 \mathrm{rpm}$; aeration rate $=1.0 \mathrm{vvm}$.

\section{Method accuracy at different OTRs}

Next, the validity of the off-gas oxygen method was tested at a range of reaction rates in order to ascertain a feasible operating window under which it might be applied. A possible strategy to fix the reaction rate was to ensure the reaction was purely limited by oxygen transfer kinetics and not enzyme kinetics. In order to do so, each experiment was dosed with a surplus of GOx. The reaction performance could therefore be controlled by the OTR by adjusting physical reactor parameters: stirrer speed and aeration rate, independent of enzyme activity. In all instances, except under the highest OTR $\left(98.89 \pm 1.44 \mathrm{mmol} \mathrm{L}^{-1} \mathrm{~h}^{-1}\right), 200 \mathrm{mg} \mathrm{L}^{-1}$ GOx was sufficient to reach this oxygen limited reaction state, which was confirmed by observing the same kinetics in a duplicate experiment under the same conditions with double the enzyme dose (data not shown). The upper limit of this operating window was dictated by the maximum allowable reactor settings. Increasing scale or changing the reactor will therefore redefine the window under which this method may be applied.

Clearly the accuracy of the method varies with the ability to match oxygen supply and consumption in the reaction. If either the reaction rate or oxygen transfer rate are too low, then an inadequate response from the gas sensors may lead to inaccurate kinetic predictions. On this basis we reasoned that a useful operating range for the method must be investigated. The range of OTRs and results are summarised in Table 1. Narrow 95\% confidence intervals $(<3 \%$ on average) point towards a high precision of the method. This may be attributed to the large sample size of data that was used to calculate initial rates, an inherent benefit of using such online measurements with a quick data collection capacity.

Figure 3 illustrates the accuracy of rate estimations based on the online method relative to those obtained through HPLC analyses in a parity plot. For the sake of generality, initial reaction rates have been presented as space-time yields (STYs) in $\mathrm{g} \mathrm{L}^{-1} \mathrm{~h}$ 1 . The two methods show a high degree of linear correlation $\left(R^{2}=0.9556\right)$. The method appears to have a slight bias towards overestimating the reaction rate; however, most of the data points for the two methods fall within $85 \%$ of each other.

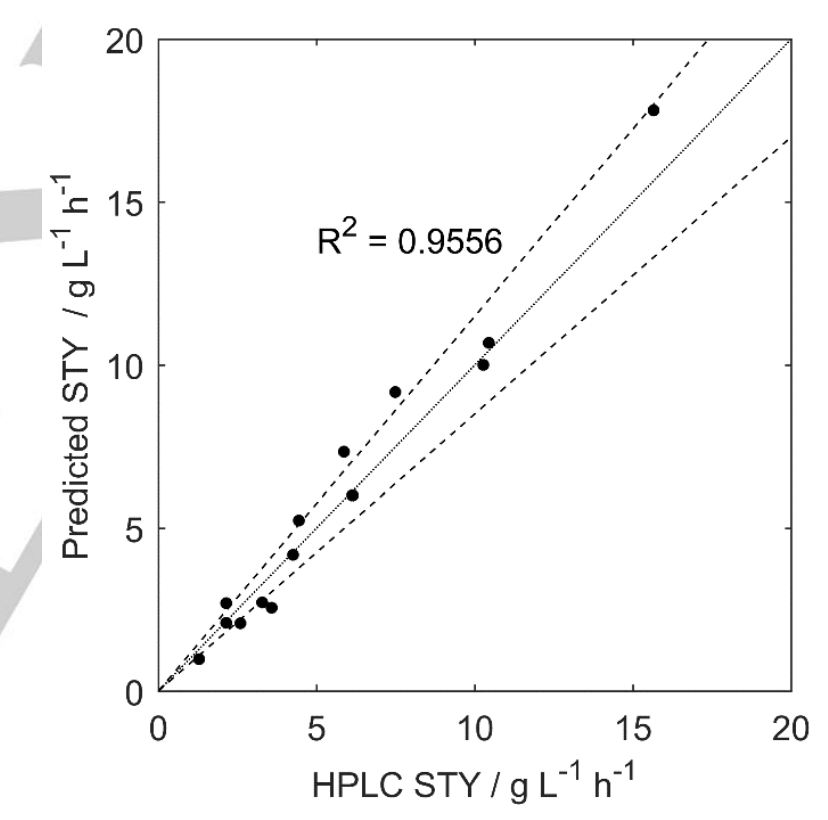

Figure 3. Parity plot of space-time yields (STYs; productivities) measured by HPLC vs. those predicted by oxygen mass balance. Data were taken from all experiments and were adjusted to represent more typical reactions where the stoichiometric coefficient of oxygen to product is equal. Dashed lines indicate $85 \%$ similarity; dotted line indicates unity. 


\begin{tabular}{|c|c|c|c|c|c|}
\hline Agitation Rate & $\begin{array}{l}\text { Aeration } \\
\text { Rate }\end{array}$ & $\begin{array}{l}\text { Measured } R_{02} / \\
\mathrm{mmol} \mathrm{L}^{-1} \mathrm{~h}^{-1}\end{array}$ & $\begin{array}{l}\text { Predicted R R } \text { gucoose / } \\
\mathrm{mmol} \mathrm{L}^{-1} \mathrm{~h}^{-1}\end{array}$ & $\begin{array}{l}\mathrm{HPLC} R_{\text {glucose }} \\
\mathrm{mmol} \mathrm{L}^{-1} \mathrm{~h}^{-1}\end{array}$ & $\begin{array}{l}\text { Accuracy / } \\
\%\end{array}$ \\
\hline \multirow{3}{*}{$\begin{array}{l}500 \mathrm{rpm} \\
\left(P / V=0.1 \mathrm{~kW} \mathrm{~m}^{-3}\right)\end{array}$} & $0.5 \mathrm{vvm}$ & $15.12 \pm 1.07$ & $30.25 \pm 2.14$ & $36.37 \pm 0.32$ & 83.2 \\
\hline & $1.0 \mathrm{vvm}$ & $23.20 \pm 1.08$ & $46.39 \pm 2.17$ & $47.23 \pm 0.15$ & 98.2 \\
\hline & $2.0 \mathrm{vvm}$ & $40.76 \pm 0.91$ & $81.52 \pm 1.82$ & $65.12 \pm 0.53$ & 74.8 \\
\hline \multirow{4}{*}{$\begin{array}{l}1000 \mathrm{rpm} \\
\left(P / V=0.8 \mathrm{~kW} \mathrm{~m}^{-3}\right)\end{array}$} & $0.5 \mathrm{vvm}$ & $50.93 \pm 0.45$ & $101.87 \pm 0.91$ & $83.09 \pm 2.02$ & 77.4 \\
\hline & $1.0 \mathrm{vvm}$ & $55.56 \pm 0.62$ & $111.12 \pm 1.23$ & $113.99 \pm 2.77$ & 97.5 \\
\hline & $2.0 \mathrm{vvm}$ & $59.31 \pm 1.27$ & $118.61 \pm 2.54$ & $116.00 \pm 1.00$ & 97.8 \\
\hline & $2.0 \mathrm{vvm}^{[\mathrm{a}]}$ & $98.89 \pm 1.44$ & $197.79 \pm 2.88$ & $173.71 \pm 3.02$ & 86.1 \\
\hline
\end{tabular}

[a] Double GOx dose $=400 \mathrm{mg} \mathrm{L}^{-1}$.

\section{Sensitivity to dynamic changes}

The response of the off-gas method towards dynamic rate changes was observed by starting a reaction with $30 \mathrm{mg} \mathrm{L}^{-1} \mathrm{GOx}$ and then doubling the reaction rate after some time by dosing the reaction with a further $30 \mathrm{mg} \mathrm{L}^{-1} \mathrm{GOx}$ (Table 2). Oxygen supply was adequate at a volumetric mass transfer coefficient $\left(k_{L} a\right)$ of $85 \mathrm{~h}^{-1}$ owing to the fact that no rate limitations were observed. Although a slightly higher reaction rate was predicted by the gasphase mass balance method when compared to that obtained by HPLC analyses, the increase in rate after doubling the enzyme loading was exactly as expected at 1.95 -fold the previous value. Therefore, we concluded that the method could accurately predict dynamic rate changes caused by the corresponding enzyme addition. It follows that the method could therefore also cope with dynamic rate variations encountered in other oxidation reactions. Generally it was found that the sensors had a response time of less than $5 \mathrm{~s}$ to disturbances in steady-states, although this is dependent on the gas holdup of the reactor.

Table 2. Initial reaction rates as a function of dynamic enzyme dose from oxygen mass balance and HPLC analysis.

\begin{tabular}{lllll}
\hline $\begin{array}{l}\text { GOx } \\
\text { Dose }\end{array}$ & $\begin{array}{l}\text { Predicted } R_{\text {glucose }} \\
/ \mathrm{mmol} \mathrm{L}^{-1} \mathrm{~h}^{-1}\end{array}$ & $\begin{array}{l}\text { Predicted } \\
R_{\text {glucose }} \\
\text { Increase }\end{array}$ & $\begin{array}{l}\text { HPLC } R_{\text {glucose }} / \\
\mathrm{mmol} \mathrm{L}^{-1} \mathrm{~h}^{-1}\end{array}$ & $\begin{array}{l}\text { HPLC } \\
R_{\text {glucose }} \\
\text { Increase }\end{array}$ \\
\hline $30 \mathrm{mg} \mathrm{L}^{-1}$ & 29.91 & $1.95 \mathrm{x}$ & 23.81 & $2.07 \mathrm{x}$ \\
$60 \mathrm{mg} \mathrm{L}^{-1}$ & 58.18 & 49.27 & \\
\hline
\end{tabular}

\section{Comparison with online methods}

Lastly, the off-gas method was put into context with two other online methods that can be used to monitor reaction kinetics: DOT measurements and alkali titration for $\mathrm{pH}$ maintenance.
Predicting rates by dissolved oxygen measurements requires an estimation of the $k_{L} a$ of the system under the conditions that are to be run in a time-course experiment. In this instance, the oxygen transfer characteristics of the $150 \mathrm{~mL}$ reactor used were estimated using the dynamic gassing-out method ${ }^{[25]}$ through dissolved oxygen measurements under standard conditions: in water at $25^{\circ} \mathrm{C}$ and $1 \mathrm{~atm}$. The $k_{L} a$ as a function of stirring speed and aeration rate is shown in Figure 4.

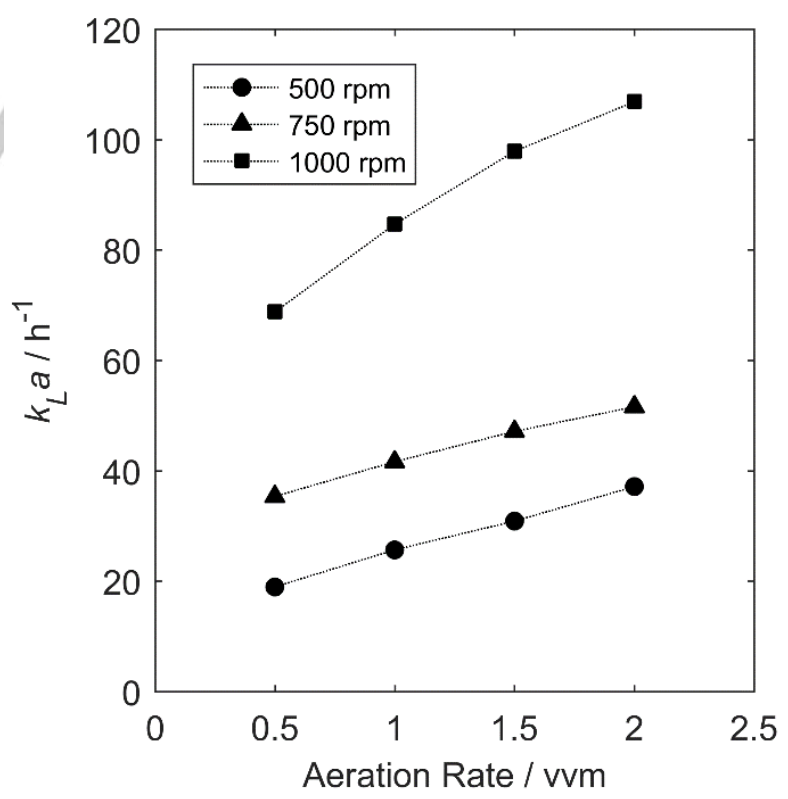

Figure 4. Average $k_{L}$ a as a function of stirring speed and aeration rate in $150 \mathrm{~mL}$ water at $25^{\circ} \mathrm{C}$ and $1 \mathrm{~atm}$ (SD $<1 \%$ in all instances; $n=5$ ). 


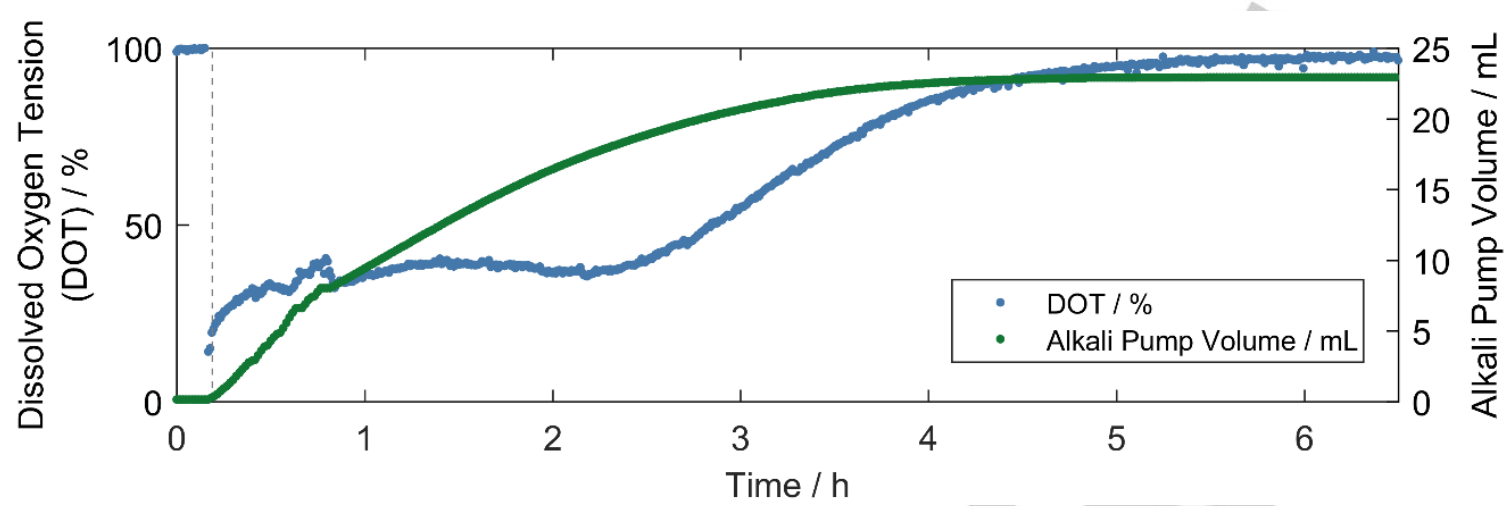

Figure 5. Time-course reaction performed in the absence of buffer solution with $1 \mathrm{M} \mathrm{NaOH}$ as base titrant. The grey line indicates reaction initiation by the addition of $200 \mathrm{mg} \mathrm{L}^{-1} \mathrm{GOx}$. Dissolved oxygen tension (DOT) is shown in blue and the net alkali pump volume is shown in green. Agitation rate $=1000 \mathrm{rpm}$; aeration rate $=1.0 \mathrm{vvm}$.

Measurements of the dissolved oxygen tension over time during an experiment (Figure 5) converted through Henry's law to oxygen concentrations in the liquid medium allow the OTR to be calculated at each instance of the experiment. The prediction of glucose consumption follows from the calculated OTR and reaction stoichiometry (Figure 2 ).

The number of moles of oxygen or substrate consumed during such a reaction should also correlate with the number of moles of $\mathrm{NaOH}$ base titrated to maintain the $\mathrm{pH}$ in an unbuffered system since the resultant reaction product is an acid. The number of moles of base added can be calculated from the measured alkali pump volume and known concentration of the base solution (Figure 5).

The glucose consumption kinetics predicted by each method and those established by HPLC analyses are presented in Figure 2 and initial rates compared in Table 3. Each method was able to follow the reaction to an extent, although with varying degrees of accuracy. In terms of both initial rate and predicted kinetics over the full time-course of the experiment, the gas-phase mass balance method was most comparable to HPLC analysis, which was considered to be the benchmark being the standard analytical method for this reaction. A weakness of predictions by dissolved oxygen measurements is that an accurate measurement of $k\llcorner a$ under reaction conditions is essential, as opposed to a $k_{L} a$ estimated under standard conventions. $k_{L} a$ is dependent on medium properties such as the presence of salts, sugars or the enzyme itself, ${ }^{[26]}$ which could be a reason for an inaccurate $k\llcorner a$ estimate found under conventional standard conditions using the dynamic gassing out method. Using oversaturated enzyme reactions (i.e. reactions performed under OTR limited conditions) to measure $k_{L} a$ was postulated to be superior to conventional methods such as the dynamic gassing out method because it inherently incorporates a more realistic medium composition, required by the enzymatic reaction itself. ${ }^{[27 a, b]}$ In the case of this experiment, the $k$ La during reaction is closer to $96.7 \mathrm{~h}^{-1}$ rather than the estimated $84.7 \mathrm{~h}^{-1}$, which is why the predicted glucose consumption kinetics were slower than those obtained by HPLC analyses. The accuracy of the $\mathrm{pH}$ titration method for kinetic predictions was most likely reduced due to the difficulty in making an accurate measurement of the peristaltic pump flow rate. Furthermore, any residual buffer salts in solution could cause a deviation of alkaline addition from that which is specifically required to neutralise the acidic product formation. Clearly a method relying on $\mathrm{pH}$ titration is less generic because not all reactions feature acids or bases. In any case, the method of gas-phase kinetic prediction does not suffer from these drawbacks and can be applied more generally to any oxidation reaction without the need for liquid-phase measurements.

Table 3. Comparison of initial rates predicted by three online methods for oxidation kinetic predictions $\left(R_{x}=\right.$ mean $\left.\pm 95 \mathrm{Cl}\right)$. Accuracy reflects the closeness of each method's prediction with that of HPLC analysis.

\begin{tabular}{llll}
\hline Method & $\begin{array}{l}\text { Predicted } R_{\text {glucose }} \\
/ \mathrm{mmol} \mathrm{L}^{-1} \mathrm{~h}^{-1}\end{array}$ & $\begin{array}{l}\mathrm{HPLC} R_{\text {glucose }} / \\
\mathrm{mmol} \mathrm{L} \mathrm{h}^{-1}\end{array}$ & Accuracy / \% \\
\hline $\begin{array}{l}\text { Off-gas } \\
\text { Measurement }\end{array}$ & $66.84 \pm 1.08$ & & 98.0 \\
$\begin{array}{l}\text { DO } \\
\text { Measurement }\end{array}$ & $58.41 \pm 0.10$ & $68.19 \pm 2.05$ & 85.7 \\
$\mathrm{pH}$ Titration & $51.81 \pm 0.12$ & & 76.0 \\
\hline
\end{tabular}

\section{Method application to BVMO catalysed reactions}

To demonstrate the broader applicability of gas-phase mass balances, a further reaction catalysed by CDMO was tested featuring a poorly-water soluble substrate and product $(25.4 \pm 4.7$ and $24.2 \pm 5.7 \mathrm{mg} \mathrm{L}^{-1}$ (mean $\pm \mathrm{SD}, \mathrm{n}=3$ ), respectively), and methanol co-solvent phase to enhance substrate solubility. Due to the low solubility of both substrate and product, the reaction medium was heterogeneous, appearing turbid. Reaction monitoring by direct, liquid-phase sampling turned out to be unfeasible due to inconsistencies caused by large sample-tosample variation. However, this oxygen-dependent reaction could 
be monitored using the online off-gas method previously validated using the glucose oxidase system. An example of experimental output is shown in Figure 6.

At this enzyme loading, more than $25 \mathrm{~g} \mathrm{~L}^{-1}$ product was produced in $15 \mathrm{~h}$ resulting in a STY of $1.92 \mathrm{~g} \mathrm{~L}^{-1} \mathrm{~h}^{-1}$. An end-point analysis of the reaction medium by gas chromatography (GC-FID) confirmed the final conversion to be $92 \%$.

The oxygen consumption trend by off-gas analysis shows two distinct reaction rate periods separated by a step change at $2.5 \mathrm{~h}$. This behaviour was consistent with previous experiments and was distinct for this BVMO reaction, having not been observed in reactions with GOx. We hypothesise that this may be caused by loss of methanol co-solvent by gas stripping. There may exist a critical surface tension or methanol concentration under which poorly-soluble ketone or oxygen availability becomes limiting. A different cause for reaction rate decrease may be due to product inhibition after a limiting amount of product has formed during reaction. However, this is less likely to be the case considering the sharp step change nature of rate response.

Regardless, such an experiment highlights the strength of such an online method to discover kinetic effects in real-time, which is difficult to achieve through discrete sampling and analysis. Furthermore, these results satisfy the scope of demonstrating the more general application of gas-phase mass balances to other reaction systems.

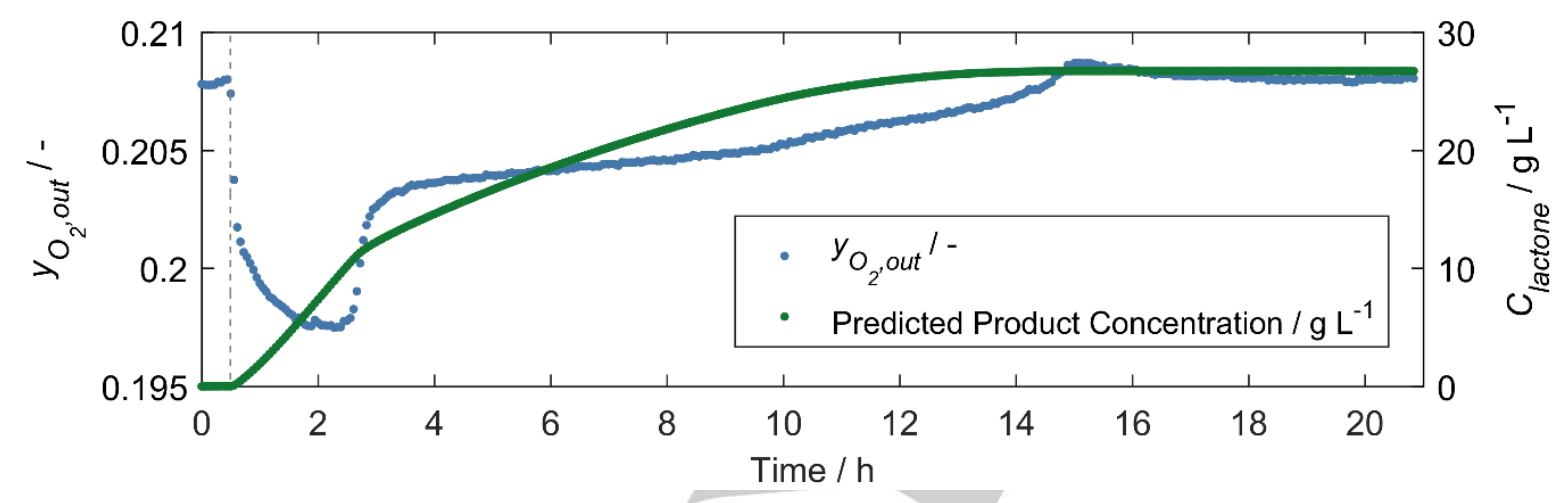

Figure 6. Reaction kinetics of the oxidation of cyclopentadecanone to cyclopentadecanolide catalysed by CDMO. The grey line indicates reaction initiation by the addition of $5 \%(\mathrm{v} / \mathrm{v})$ CDMO cell free extract. The fraction of oxygen in the outlet gas stream ( $y_{02, \text { out }}$ ) is shown in blue and the predicted concentration of lactone product made by oxygen mass balance is shown in green.

\section{Effects of scale, limitations and advantages}

One challenge with the gas-phase method is the measurable net difference in molar oxygen flow between reactor inlet and outlet. Assuming considerable reaction rate, the net difference will depend on both $k_{L} a$ and gas-phase holdup, both of which increase with scale. ${ }^{[28]}$ Since $k\llcorner a$ values are higher at larger scales, so too OTRs and therefore overall reaction rates are vastly improved from smaller-scales if oxygen mass transfer has been found to be limiting. Therefore, it is expected that method accuracy should improve with scale due to more oxygen being consumed in reaction. The online method could also prove advantageous in large-scale applications for monitoring and control of (bio)oxidation reactions where manual sampling of the reactor could be challenging due to e.g. overpressure, sterility, heterogeneity, safety, manpower or analytics. However, larger gas holdups expected at industrial scales might also affect the dynamic sensitivity of the method (i.e. the ability to detect sudden changes). Because of the reliance of the method on a net difference in molar oxygen in the gas-phase, it is also doubtful that this method will be as accurate at space-time yields lower than those encountered in this study $\left(<1 \mathrm{~g} \mathrm{~L}^{-1} \mathrm{~h}^{-1}\right)$, which might be prevalent at smaller scales.

If a reactor overpressure or increased temperature is required, deviations from standard conditions $\left(1 \mathrm{~atm}, 25^{\circ} \mathrm{C}\right)$ will be seen. Such effects from these cases could be accounted for by adjusting the assumptions behind calculating molar quantities using volumetric flow measurements and the ideal gas law (see Theory section for more details).

The online methodology followed in this paper could potentially be automated to a degree by generating an appropriate software; doing so would enable an increased throughput for experiments.

With respect to the generality of the method, only the oxygen consumption/liberation from a net reaction is measured and not from individual half-reactions as is the case of (oxygen) uncoupling from product formation (e.g. with P450 monooxygenases) or when multiple reaction products are formed. Therefore, the black box approach to estimating kinetics from oxygen mass balances will make it difficult to distinguish uncoupling or to follow enantioselective reactions. In such instances, direct substrate/product analyses would remain the benchmark for performing kinetic characterisations. However, this method should find useful application with systems involving challenging substrates where liquid-phase sampling is made impractical (e.g. heterogeneous reactions or enzyme-catalysed surface modifications of solids ${ }^{[29]}$ ) as exemplified with the BVMO case described in the previous section. 


\section{Conclusions}

This study proves that the method of gas-phase oxygen mass balance is able to adequately predict bio-oxidation kinetics. In order to apply the method, an operating window of space-time yields under which it may be applied must be established. In this study, this window was found to be between $1-15 \mathrm{~g} \mathrm{~L}^{-1} \mathrm{~h}^{-1}$, which was inherently linked to the oxygen transfer capabilities of the labscale apparatus used in this study. Therefore, the generic concept of using oxygen mass balance to determine kinetics holds, and this could find application in the studies of heterogeneous reactions, as well as for industrial measurement and control of oxidation processes.

\section{Experimental Section}

Theory

A black box approach over the gas-phase during biocatalytic oxidation was applied (Figure 7).

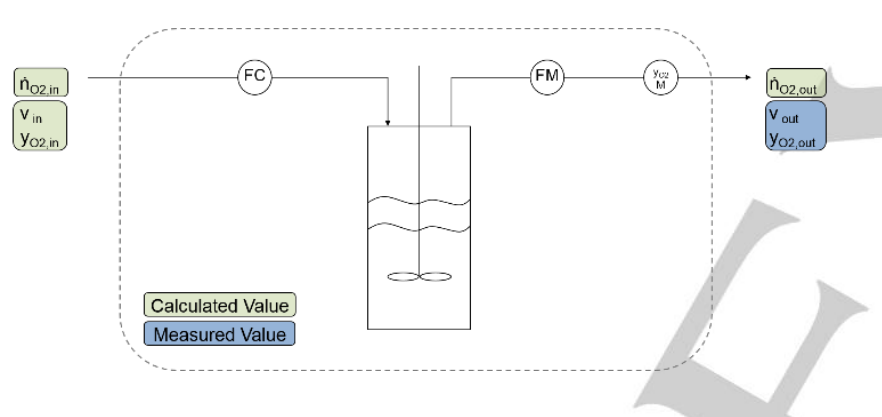

Figure 7. Black box schematic of reaction apparatus. FC = gas flow controller; $\mathrm{FM}$ = gas flow meter; yo2 $\mathrm{M}=$ gas-phase oxygen fraction meter.

The number of moles of oxygen in the gas outlet stream, $\dot{n}_{\circ 2, \text { out }} / \mathrm{mol} \mathrm{h}^{-1}$, can be calculated by applying the ideal gas law to the total volumetric gas flow rate, $v_{\text {out }} / \mathrm{sL} \mathrm{h}^{-1}$, and oxygen fraction in the gas-phase, yoz,out / -, which are measured variables:

$$
\dot{n}_{\mathrm{O}_{2} \text { out }}=\frac{P \cdot v_{\text {out }}}{R T} \times y_{\mathrm{O}_{2}, \text { out }}
$$

The number of moles of oxygen flowing into the system is calculated during a steady-state where no reaction is taking place because the following simplification holds:

$$
\dot{n}_{\mathrm{O}_{2}, \text { in }}=\dot{n}_{\mathrm{O}_{2}, \text { out }}
$$

During reaction, the oxygen consumption rate, $R_{02} / \mathrm{mol} \mathrm{L}^{-1} \mathrm{~h}^{-1}$, can then be found by mass balance, and the glucose consumption rate from reaction stoichiometry (Scheme 1):

$$
R_{\mathrm{O}_{2}}=\frac{d C_{\mathrm{O}_{2}}}{d t}=\frac{\dot{n}_{\mathrm{O}_{2}, \text { in }}-\dot{n}_{\mathrm{O}_{2} \text { out }}}{V}=\frac{1}{2} R_{\text {glucose }}
$$

The initial rate of reaction is found in a similar manner from an initial portion of data when the reaction velocity can be considered linear. Replacing $\dot{n}_{O 2, \text { out }}$ with an averaged oxygen flow rate, n'oz,avg, observed during this period of steady-state reaction, allows the calculation of the initial rate. The $95 \%$ confidence intervals were determined using the total sample size of data that were averaged to calculate each initial rate $(n>100$ in almost all instances).

The off-gas mass balance can also be combined with classic two-film theory to yield the following overall expression, where $k_{L} a / h^{-1}$ is the overall volumetric mass transfer coefficient, and $\mathrm{C}_{\mathrm{O} 2}^{*}$ and $\mathrm{CO}_{\mathrm{O}} / \mathrm{mol} \mathrm{L}^{-1}$ are the dissolved oxygen (DO) concentrations at saturation and in the bulk medium, respectively:

$$
\frac{\dot{n}_{O_{2}, \text { in }}-\dot{n}_{O_{2}, \text { out }}}{V}=\frac{d C_{O_{2}}}{d t}=k_{L} a\left(C^{*} O_{2}-C_{O_{2}}\right)
$$

\section{Reagents}

All reagents were of analytical grade and supplied by Sigma-Aldrich (Buchs, Switzerland). HiQ® Synthetic Air 5.0 was supplied by AGA A/S (Copenhagen, Denmark). Lyophilised catalase from bovine liver $\left(\geq 2000 \mathrm{U} \mathrm{mg}^{-1}\right.$; EC 1.11.1.6) and superoxide dismutase (SOD) from bovine erythrocytes ( $\geq 3000 \mathrm{U} \mathrm{mg}^{-1}$; EC 1.15.1.1) were purchased from Sigma-Aldrich. Glucose oxidase from Aspergillus niger (EC 1.1.3.4) was provided by DuPont Industrial Biosciences (Wageningen, The Netherlands) in the form of lyophilised cell free extract. Cyclododecanone monooxygenase from Rhodococcus ruber SC1 (EC 1.14.13.x) was provided by InnoSyn BV (Geleen, The Netherlands) in the form of cell free extract. Lyophilised glucose dehydrogenase (EC 1.1.1.47) for NADPH cofactor regeneration was provided as $\mathrm{GDH} 280$ by evoxx technologies $\mathrm{GmbH}$ (Monheim am Rhein, Germany).

\section{GOx batch reaction conditions}

Experiments were performed in a sealed $250 \mathrm{~mL}$ bioreactor with a working volume of $150 \mathrm{~mL}$ (MiniBio with my-Control software from Applikon Biotechnology (Delft, The Netherlands)). The bioreactor included stirring (500-1000 rpm), aeration (0.5-2.0 aeration volumes per reactor volume per minute (vvm)), $\mathrm{pH}$ and temperature control capabilities. The operating temperature was maintained at $25^{\circ} \mathrm{C}$ and $\mathrm{pH}$ at 7.5 by potassium phosphate buffer $(200 \mathrm{mM})$. pH-stat experiments by titration of $\mathrm{NaOH}$ $(1 \mathrm{M})$ were performed in the absence of buffer. Reaction kinetics were determined through complete oxidation of glucose $(200 \mathrm{mM})$ by the addition of, unless otherwise stated, GOx $\left(200 \mathrm{mg} \mathrm{L}^{-1}\right)$ and catalase $\left(10000 \mathrm{UL}^{-1}\right)$ to ensure total $\mathrm{H}_{2} \mathrm{O}_{2}$ removal. Samples of $1 \mathrm{~mL}$ were periodically taken for analysis by HPLC. Dissolved oxygen in the liquidphase was measured by a Solvent-Resistant Oxygen Probe (PyroScience $\mathrm{GmbH}$, Aachen, Germany). To improve measurement accuracy, the gasphase at the reactor outlet was dried by use of a condenser and sequential drying tube filled with silica drying beads before being passed through a Smart-Trak $\AA 50$ Series Digital Mass Flow Meter (Sierra Instruments, Inc., Monterey $\mathrm{CA}, \mathrm{USA}$ ) and BluelnOne $\mathrm{CO}_{2} / \mathrm{O}_{2}$ Gas Analyser (BlueSens gas analyser $\mathrm{GmbH}$, Herten, Germany).

\section{BVMO batch reaction conditions}

The oxidation of macrocyclic ketones to lactones catalysed by CDMO were also performed in the same bioreactor used for GOx reactions (working volume of $150 \mathrm{~mL}$ ). Reaction temperature was controlled at $30^{\circ} \mathrm{C}$ and $\mathrm{pH}$ at 7.5 by $\mathrm{NaOH}(6 \mathrm{M})$ addition and potassium phosphate buffer $(100 \mathrm{mM})$. D-Glucose $(200 \mathrm{mM})$ and GDH280 $\left(25 \mathrm{U} \mathrm{mL}^{-1}\right)$ were used for cofactor regeneration. $\mathrm{NADP}^{+}(2.5 \mathrm{mM}), \mathrm{FAD}(0.1 \mathrm{mM})$, catalase $\left(150 \mathrm{U} \mathrm{mL}^{-1}\right)$, and 
SOD $\left(20 \mathrm{U} \mathrm{mL}^{-1}\right)$ were for their stabilising effect on BVMOs. ${ }^{[30]}$ Antifoam $204(0.5 \% \quad(\mathrm{v} / \mathrm{v}))$ was added to prevent foam formation. Cyclopentadecanone substrate $(100 \mathrm{mM})$ was added to the reaction medium dissolved in methanol co-solvent $(20 \%(\mathrm{v} / \mathrm{v}))$. Lastly, the reaction was initiated by the addition of CDMO cell free extract $(5 \%(\mathrm{v} / \mathrm{v}))$.

\section{GC analysis}

End-point analyses of the BVMO experiment reaction medium could only be carried out after reaction completion due to the formation of a welldispersed emulsion. 5 replicate samples of $1 \mathrm{~mL}$ were drawn from the reactor and substrate/product extraction was facilitated by 1:1 volumes of ethyl acetate containing naphthalene $\left(1.5 \mathrm{~g} \mathrm{~L}^{-1}\right)$ as an internal standard. After vigorous mixing by vortex for $30 \mathrm{~s}$ and separation of organic from aqueous components by centrifugation, $300 \mu \mathrm{L}$ of the organic fraction was analysed by Clarus 500 GC-FID (Perkin Elmer). $1 \mu \mathrm{L}$ of sample was injected into an Elite- 5 column (Perkin Elmer) where the oven temperature was ramped from $150^{\circ} \mathrm{C}$ to $200^{\circ} \mathrm{C}$ at $4{ }^{\circ} \mathrm{C}$ per minute and thereafter at a rate of $40^{\circ} \mathrm{C}$ per minute to a final isotherm at $300^{\circ} \mathrm{C}$ for 1 minute. $0.60 \mathrm{~mL} \mathrm{~min}^{-1}$ helium with a split ratio of $10: 1$ was used as carrier gas. Injector and detector temperatures were maintained at $280^{\circ} \mathrm{C}$ throughout. Experimental substrate and product concentrations were determined using a standard curve generated by subjecting samples of known concentrations to the same solvent extraction procedure.

\section{HPLC analysis}

Glucose analyses were carried out by HPLC following the identical procedure detailed by Toftgaard Pedersen et al. ${ }^{[31]}$

\section{Solubility measurements}

The solubility of the macrocyclic ketone and lactone, cyclopentadecanone and cyclopentadecanolide, was measured in triplicate by accurately weighing an amount of each into a $1 \mathrm{~L}$ volumetric flask containing $\mathrm{dH}_{2} \mathrm{O}$. The solution was mixed by orbital shaking and incubated at $30^{\circ} \mathrm{C}$ for 3 days to allow for equilibration. The mixtures were then filtered, dried, and weighed again. The difference in mass from beginning to end was taken to be the amount dissolved in water (solubility).

\section{Acknowledgements}

"The research for this work has received funding from the European Union (EU) project ROBOX (grant agreement $n^{\circ}$ 635734) under EU's Horizon 2020 Programme Research and Innovation actions H2020-LEIT BIO-2014-1. Any statements herein reflect only the author's views. The European Union is not liable for any use that may be made of the information contained herein."

Rolf $\mathrm{H}$. Ringborg is thanked for helping set up the off-gas sensors through his expertise in LabVIEW.

Keywords: biocatalysis $\bullet$ oxidoreductases $•$ oxidation $•$ kinetics $•$ online methods

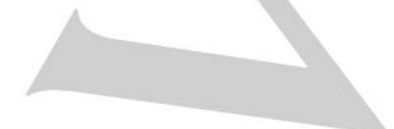

[1] a) D. G. Blackmond, Angew. Chem. Int. Ed. 2005, 44, 4302-4320; b) D. G. Blackmond, J. Am. Chem. Soc. 2015, 137, 10852-10866.

[2] P. Tufvesson, J. Lima-Ramos, J. S. Jensen, N. Al-Haque, W. Neto, J. M. Woodley, Biotechnol. Bioeng. 2011, 108, 1479-1493.

[3] J. M. Woodley, Curr. Opin. Chem. Biol. 2013, 17, 310-316.

[4] R. H. Ringborg, A. Toftgaard Pedersen, J. M. Woodley, ChemCatChem 2017, doi:10.1002/cctc.201700811.

[5] J. Lima-Ramos, P. Tufvesson, J. M. Woodley, Green Process Synth. 2014, 3, 195-213.

[6] R. H. Ringborg, J. M. Woodley, React. Chem. Eng. 2016, 1, 10-22.

[7] M. D. Truppo, ACS Med. Chem. Lett. 2017, 8, 476-480.

[8] A. Schmid, J. S. Dordick, B. Hauer, A. Kiener, M. Wubbolts, B. Witholt, Nature 2001, 409, 258-268.

[9] R. A. Sheldon, Green Chem. 2017, 19, 18-43.

[10] J. Lu, M. J. Lazzaroni, J. P. Hallett, A. S. Bommarius, C. L. Liotta, C. A Eckert, Ind. Eng. Chem. Res. 2004, 43, 1586-1590.

[11] F. Uthoff, A. Reimer, A. Liese, H. Gröger, Sustainable Chem. Pharm. 2017, 5, $42-45$.

[12] A. Reimer, S. Wedde, S. Staudt, S. Schmidt, D. Höffer, W. Hummel, U. Kragl , U. T. Bornscheuer, H. Gröger, J. Heterocyclic Chem. 2017, 54, 391-396.

[13] P. Süss, S. lllner, J. von Langermann, S. Borchert, U. T. Bornscheuer, R. Wardenga, U. Kragl, Org. Process Res. Dev. 2014, 18, 897-903.

[14] P. Dominguez de Maria, F. Hollmann, Front. Microbiol. 2015, 6, 1257.

[15] K. Faber in Biotransformations in Organic Chemistry, Springer-Verlag, Berlin Heidelberg, 2011, pp. 31-313.

[16] F. Hollmann, I. W. C. E. Arends, K. Buehler, A. Schallmey, B. Bühler, Green Chem. 2011, 13, 226-265.

[17] N. J. Turner, Chem. Rev. 2011, 111, 4073-4087.

[18] W. Kroutil, H. Mang, K. Edegger, K. Faber, Adv. Synth. Catal. 2004, 346, 125-142.

[19] B. Bühler, I. Bollhalder, B. Hauer, B. Witholt, A. Schmid, Biotechnol. Bioeng. 2003, 82, 833-842

[20] J. Kappeler, W. Gujer, Wat. Sci. Tech. 1992, 25, 125-139.

[21] a) D. A. Mitchell, M. Berovic, N. Krieger in Advances in Biochemical Engineering/Biotechnology, Vol. 68 (Ed.: T. Scheper), Springer-Verlag, Berlin Heidelberg, 2000, pp. 61-138; b) E. Gumbira-Sa'id, P. F. Greenfield, D. A. Mitchell, H. W. Doelle, Biotechnol. Adv. 1993, 11, 599 610.

[22] J. Villadsen in Fundamental Bioengineering, Vol. 1 (Eds.: S. Y. Lee, J. Nielsen, G. Stephanopoulos), Wiley-VCH, Germany, 2016, pp. 5-16.

[23] J. D. Schumacher, R. M. Fakoussa, Appl. Microbiol. Biotechnol. 1999, 52, 85-90.

[24] K. Kostichka, S. M. Thomas, K. J. Gibson, V. Nagarajan, Q. Cheng, J. Bacteriol. 2001, 183, 6478-6486.

[25] M. M. Lopes de Figueiredo, P. H. Calderbank, Chem. Eng. Sci. 1979, 34 , 1333-1338.

[26] N. Pulido-Mayoral, E. Galindo, Biotechnol. Prog. 2004, 20, 1608-1613.

[27] a) K. Ortiz-Ochoa, S. D. Doig, F. M. Ward, F. Baganz, Biochem. Eng. J. 2005, 25, 63-68; b) F. Garcia-Ochoa, E. Gomez, Biotechnol. Adv. 2009, 27, 153-176.

[28] S. M. Stocks in Microbial Production of Food Ingredients, Enzymes and Nutraceuticals, (Ed.: S. Hughes), Woodhead Publishing, USA, 2013, pp. 144-172.

[29] G. Fischer-Colbrie, S. Heumann, G. Guebitz in Modified Fibers with Medical and Specialty Applications, Vol. 1 (Eds.: J. V. Edwards, G. Buschle-Diller, S. C. Goheen), Springer, Netherlands, 2006, pp. 181-189.

[30] L. C. P. Goncalves, D. Kracher, S. Milker, M. J. Fink, F. Rudroff, R. Ludwig, A. S. Bommarius, M. D. Mihovilovic, Adv, Synth. Catal. 2017, 359, 2121-2131.

[31] A. Toftgaard Pedersen, T. M. de Carvalho, E. Sutherland, G. Rehn, R. Ashe, J. M. Woodley, Biotechnol. Bioeng. 2017, 114, 1222-1230. 


\section{WILEY-VCH}

\section{FULL PAPER}

\section{Entry for the Table of Contents}

\section{FULL PAPER}

This work demonstrates a novel method for characterising the kinetics of oxygen-dependent enzymatic reactions using gas-phase oxygen mass balances.

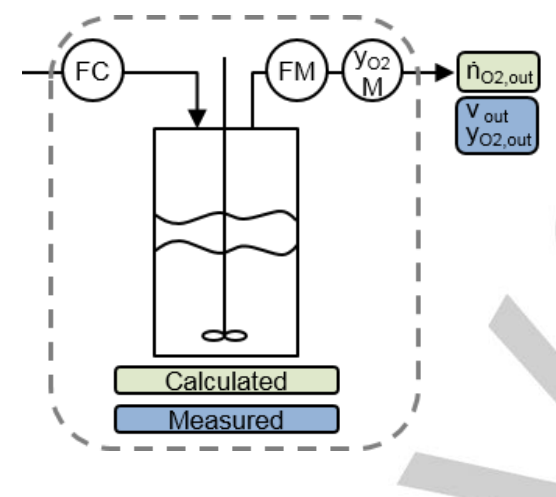

Murray P. Meissner, Mathias Nordblad, John M. Woodley*

Page No. - Page No.

Online Measurement of Oxygen-

Dependent Enzyme Reaction Kinetics 